\title{
PROFIL PENDERITA IKTERUS NEONATORUM YANG DIRAWAT DIBAGIAN KESEHATAN ANAK RSU ANUTAPURA DAN RSUD UNDATA PALU TAHUN 2019-2020
}

\author{
Andi Handriyati $^{{ }^{*},}$, Dewi Rizkiyah Anugrahini ${ }^{1}$, Fathurrahman Muiz ${ }^{1}$ \\ ${ }^{1}$ Program Studi Pendidikan Dokter, Fakultas Kedokteran Universitas Alkhairat, Jl. Diponegoro No. 39 \\ Palu 94221, Sulawesi Tengah, Indonesia \\ *Corresponding author: Telp +62 821-9363-5235 email: riapediatric@ gmail.com
}

\begin{abstract}
ABSTRAK
Penyakit Ikterus Neonatorum perlu diperhatikan dan segera ditangani dengan maksud untuk mengurangi angka kejadian mortalitas dan morbiditas penderita ikterus neonatorum di Kota Palu. Penelitian ini bertujuan untuk mengetahui Profil Penderita Ikterus Neonatorum Yang Dirawat Inap di Bagian Kesehatan Anak RSU Anutapura dan RSUD Undata Palu tahun 20192020. Metode penelitian ini bersifat deskriptif kategorik dengan menggunakan data primer berdasarkan hasil penelusuran dokumen status rekam medik penderita Penderita Ikterus Neonatorum yang dirawat inap di Bagian Kesehatan Anak RSU Anutapura dan RSUD Undata Palu tahun 2019-2020. Hasil menunjukkan bahwa selama periode November 2019 sampai Januari tahun 2020, di RSU Anutapura Palu dan RSUD Undata palu telah dirawat 48 orang penderita Ikterus Neonatorum. Ditemukan bayi lahir kurang bulan sebagai kasus terbanyak sebanyak (68,8\%), diikuti bayi lahir cukup bulan (31,3\%). Berdasarkan berat badan lahir terbanyak pada bayi berat lahir rendah sebanyak (54,2\%), diikuti oleh berat lahir cukup $(35,4 \%)$, dan bayi berat lahir sangat rendah(10,4\%). Berdasarkan jenis kelamin penderita yang berjenis kelamin laki- laki sebanyak (64,6\%), diikuti oleh bayi perempuan $(35,4 \%)$. Disimpulkan bahwa Angka kejadian penderita Penderita Ikterus Neonatorum Yang Dirawat Inap di Bagian Kesehatan Anak RSU Anutapura dan RSUD Undata Palu tahun 2019- 2020 sebanyak 48 orang. Penderita kebanyakan bayi prematur, berat badan lahir cukup, bayi laki-laki.
\end{abstract}

Kata Kunci: Ikterus Neonatorum, Kesehatan anak, RSU Anutapura dan RSUD Undata

\begin{abstract}
Neonatal jaundice needs to be considered and treated immediately to reducing the incidence of mortality and morbidity of patients with neonatal jaundice in Palu City. This study aims to determine the profile of patients with neonatal jaundice who are hospitalized in the Child Health Section of Anutapura Hospital and Undata Hospital Palu in 2019-2020. This research method is descriptive categorical using primary data based on the results of searching medical record status documents for patients with neonatal jaundice who are hospitalized in the Children's Health Section of Anutapura Hospital and Undata Hospital Palu in 2019-2020. The results show that during the period from November 2019 to January 2020, at the Anutapura Hospital and the Undata Hospital in Palu, 48 patients with neonatal jaundice were treated. It was found that preterm babies were the most common cases (68.8\%), followed by term babies (31.3\%). Based on birth weight, the most low birth weight babies (54.2\%), followed by moderate birth weight (35.4\%), and very low birth weight babies (10.4\%). Based on the sex of the patients, male (64.6\%), followed by female babies (35.4\%). It was concluded that the incidence of patients with neonatal jaundice who were hospitalized in the Children's Health Section of Anutapura Hospital and Undata Hospital Palu in 2019-2020 was 48 people. Sufferers are mostly premature babies, fair birth weight, baby boys.
\end{abstract}

Keywords: Neonatal Jaundice, Child Health, Anutapura Hospital and Undata Hospital 


\section{PENDAHULUAN}

Ikterus neonatorum adalah keadaan klinis pada bayi yang ditandai oleh pewarnaan ikterus pada kulit dan sklera akibat akumulasi bilirubin tak terkonjugasi yang berlebih. Ikterus secara klinis akan mulai tampak pada bayi baru lahir bila kadar bilirubin darah 5-7 mg/dl. ${ }^{1} \quad$ Hiperbilirubinemia berat dapat menekan konsumsi $\mathrm{O} 2$ dan menekan oksidasi fosforilasi menyebabkan kerusakan sel-sel otak, berakibat disfungsi neuronal, dan ensefalopati. Bayi-bayi dengan keadaan tersebut berisiko mengalami kematian atau kecacatan di kemudian hari.

Kejadian ikterus di Indonesia merupakan masalah terbesar pada bayi baru lahir yang sering dihadapai dengan tenaga kesehatan terjadi pada sekitar $25-50 \%$ bayi cukup bulan dan lebih tinggi pada neonatus kurang bulan. ${ }^{2}$ Menurut survey demografi kesehatan Indonesia (SDKI) pada tahun 2012 Angka kematian bayi (AKB) di Indonesia tercatat sebanyak 32 per 1000 kelahiran hidup. Kematian neonatus disebabkan oleh asfiksia (37\%), BBLR dan prematurias (34\%), sepsis (12\%), hipotermi (7\%), ikterus (6\%), postmatur (3\%), dan kelainan kongenital (1\%) per 1000 kelahiran hidup. Salah satu penyebab mortalitas pada bayi baru lahir ialah enselofati bilirunin (kern ikterus). ${ }^{3}$

Data yang diperoleh dari kamar bayi Rumah Sakit Umum (RSU) Anutapura Palu pada tahun 2014 pada bulan Agustus sampai Oktober didapatkan empat bayi yang menderita Ikterus neonatorum yang dirawat di kamar bayi RSU Anutapura Palu. Selanjutnya pada tahun 2015 pada bulan Januari sampai bulan Desember terdapat 20 bayi yang dirawat, dimana sembilan bayi perempuan dan sebelas bayi laki-laki, satu bayi yang menderita ikterus neonatorum lahir dengan BBLR (Berat Badan Lahir Rendah). Kemudian pada tahun 2016 terdapat 26 bayi yang dirawat, sepuluh diantaranya perempuan dan enam belas laki-laki, satu bayi menderita ikterus bengan BBLR. Pada tahun 2017 jumlah bayi yang menderita ikterus sebanyak 17 bayi, lima perempuan dan dua belas bayi laki-laki, satu bayi yang menderita ikterus juga lahir dengan BBLR. Selanjutnya pada tahun 2018 jumlah bayi yang menderita ikterus neonatorum berjumlah empat puluh lima bayi, dua puluh empat bayi laki- laki dan dua puluh satu bayi perempuan. Data yang diperoleh dari rekam medik RSUD Undata Palu pada tahun 2016 terdapat 24 bayi yang dirawat, sembilan diantaranya perempuan dan lima belas lakilaki. Pada tahun 2017 jumlah bayi yang menderita ikterus sebanyak 18 bayi sembilan perempuan dan sembilan bayi laki-laki. Selanjutnya pada tahun 2018 jumlah bayi yang menderita ikterus neonatorum berjumlah 27 bayi, lima belas bayi laki-laki dan dua belas bayi perempuan.

\section{METODOLOGI}

Desain penelitian yang digunakan adalah jenis penelitian deskriptif dengan metode cross sectional. Dengan melihat distribusi pasien ikterus neonatorum berdasarkan usia gestasi, berat badan lahir, jenis kelamin, sepsis dan trauma lahir. Penelitian ini dilakukan di Rumah Sakit Umum Anutapura Palu dan Rumah Sakit Umum Daerah Undata palu tahun 2019-2020 terhadap 48 data rekam medik penderita ikterus neonatorum yang dirawat di bagian kesehatan anak RSU Anutapura Palu dan RSUD Undata Palu yang dilakukan sejak November 2019 sampai Januari 2020. Pengumpulan dilakukan dengan cara observasi rekam medis untuk mengisi check list. Adapun data yang diperoleh terdiri dari usia gestasi, berat badan lahir, jenis kelamin, sepsis dan trauma lahir.

\section{HASIL DAN PEMBAHASAN}

\section{HASIL}

Profil penderita ikterus neonatorum yang dirawat inap bagian kesehatan anak di RSU anutapura dan RSUD Undata Palu pada tahun 2019-2020

Distribusi penderita ikterus neonatorum berdasarkan usia gestasi dan dapat dilihat pada tabel berikut.

Tabel 1. Distribusi penderita ikterus neonatorum berdasarkan usia gestasi

\begin{tabular}{lrll}
\hline Usia Gestasi & $\mathrm{N}$ & $\%$ \\
\hline $\begin{array}{l}\text { Cukup Bulan } \\
\text { minggu) }\end{array}$ & $(37-42$ & 15 & $31.2 \%$ \\
Kurang Bulan (<37 minggu) & 33 & $68.8 \%$ \\
\hline Total & 48 & $100,0 \%$ \\
\hline
\end{tabular}


Tabel 1. dapat diketahui dari 48 penderita ikterus neonatorum yang memenuhi kriteria sampel penelitian terbanyak ditemukan pada bayi lahir kurang bulan sebanyak $(68,8 \%)$ dan diikuti bayi lahir cukup bulansebanyak $(31,2 \%)$.

Tabel 2. Distribusi penderita ikterus neonatorum berdasarkan Jenis kelamin

\begin{tabular}{ccc}
\hline Jenis Kelamin & \multicolumn{2}{c}{ Ikterus Neonatorum } \\
\cline { 2 - 3 } & $\mathrm{N}$ & $\%$ \\
\hline Laki-laki & 31 & 64,6 \\
Perempuan & 17 & 35,4 \\
\hline Total & 48 & 100 \\
\hline
\end{tabular}

Tabel 2. dapat diketahui dari 48 penderita ikterus neonatorum yang memenuhi kriteria sampel penelitian terbanyak ditemukan pada bayi dengan jenis kelamin laki-laki sebanyak (64,6\%), dan diikuti bayi dengan jenis kelamin perempuan sebanyak $(35,4 \%)$.

Tabel 3. Distribusi penderita ikterus neonatorum berdasarkan berat badan lahir

\begin{tabular}{lcc}
\hline \multicolumn{1}{c}{ Berat Badan Lahir } & \multicolumn{2}{c}{ Ikterus } \\
& Neonatorum \\
\cline { 2 - 3 } & $\mathrm{N}$ & $\%$ \\
\hline $\begin{array}{l}\text { Berat badan lahir cukup } \\
\text { (>2500-4000 gram) }\end{array}$ & 17 & 35,4 \\
$\begin{array}{l}\text { Bayi berat lahir rendah } \\
\text { (BBLR) (1500-2500 gram) }\end{array}$ & 26 & 54,2 \\
$\begin{array}{l}\text { Bayi berat lahir sangat rendah } \\
\text { (BBLSR) (1000->15000gram) }\end{array}$ & 5 & 10,4 \\
\hline \multicolumn{1}{c}{ Total } & 48 & 100 \\
\hline
\end{tabular}

Tabel 3. dapat diketahui dari 48 penderita ikterus neonatorum yang memenuhi kriteria sampel penelitian terbanyak ditemukan pada bayi dengan bayi berat lahir rendah (BBLR) sebanyak $(54,2 \%)$, diikuti bayi berat lahir cukup sebanyak $(35,4 \%)$, dan bayi berat lahir sangat rendah (BBLSR) sebanyak $(10,4 \%)$.
Tabel 4. Distribusi penderita ikterus neonatorum berdasarkan sepsis

\begin{tabular}{ccc}
\hline Infeksi lahir & \multicolumn{2}{c}{ Ikterus Neonatorum } \\
\cline { 2 - 3 } & $\mathrm{N}$ & $\%$ \\
\hline Tidak sepsis & 48 & 100 \\
\hline Total & 48 & 100 \\
\hline
\end{tabular}

Tabel 4. dapat diketahui dari 48 penderita ikterus neonatorum yang memenuhi kriteria sampel penelitian dengan sepsis tidak didapatkan pasien sepsis.

Tabel 5. Distribusi penderita ikterus neonatorum berdasarkan trauma lahir

\begin{tabular}{ccc}
\hline Trauma lahir & \multicolumn{2}{c}{ Ikterus Neonatorum } \\
\cline { 2 - 3 } & $\mathrm{N}$ & $\%$ \\
\hline Tidak sepsis & 48 & 100 \\
\hline Total & 48 & 100 \\
\hline
\end{tabular}

Tabel 5. dapat diketahui dari 48 penderita ikterus neonatorum yang memenuhi kriteria sampel penelitian dengan trauma lahir tidak didapatkan pasien trauma.

\section{PEMBAHASAN}

1. Profil penderita Ikterus Neonatorum berdasarkan Usia Gestasi.

Dari hasil penelitian ini menurut usia gestasi terhadap kejadian ikterus neonatorum adalah tertinggi ditemukan pada bayi lahir kurang bulan sebanyak 33 bayi dengan presentase $(68,8 \%)$.

Sejalan dengan penelitian yang dilakukan oleh Maria Oliva Ratuain, Heni Puji Wahyuningsih dan Yuliasti Eka Purnamaningrum (2012) yang mengatakan bahwa penyakit ikterus neonatorum terbanyak pada bayi lahir kurang bulan sebanyak 59,1\%.Hal ini dikarenakan ikterus neonatorum pada bayi prematur disebabkan oleh penghancuran sel darah merah yang berlebihan, hati dan gastrointestinal yang belum matang. Belum cukupnya Maturasi hati setelah lahir pada bayi prematur menjadikan proses bilirubin uptake dan konjugasi menjadi lebih lambat. Kadar 
bilirubin meningkat lebih awal, kemudian mencapai puncak (5-7 hari) dan tetap meningkat lebih lama. Selain itu pada bayi prematur yang sakitakan mengalami keterlambatan dalam memberikan makanan enteral dapat membatasi motalitas usus dan kolonisasi bakteri yang mengakibatkan peningkatan sirkulasi bilirubin enterohepatik lebih lanjut. ${ }^{3}$

Metabolisme bilirubin bayi baru lahir berada dalam masa peralihan dari stadium janin ke stadium dewasa dimana pada stadium janinplasenta merupakan tempat utama eliminasi bilirubin yang larut lemak, dan pada stadium dewasa bentuk bilirubin terkonjugasi yang larut air diekskresikan dari sel hati kedalam sistem biliaris dan kemudian kedalam saluran pencernaan. ${ }^{3}$

Sejalan dengan penelitian Reisa Maulidya Tazami, Mustarim, Shalahudden Syah (2013) sebanyak 22 bayi prematur dengan presntasi $51,2 \%$ berhubungan dengan hiperbilirubinemia tak terkonjugasi pada neonatus. Aktifitas uridine difosfat glukoronil transferase hepatik jelas menurun pada bayi prematur, sehingga konjugasi bilirubin tak terkonjugasi menurun. Selain itu juga terjadi peningkatan hemolisis karena umur sel darah merah yang pendek pada bayi prematur. ${ }^{4}$

\section{Profil penderita Ikterus Neonatorum berdasarkan Jenis Kelamin.}

Dari hasil penelitian menurut jenis kelamin terhadap kejadian ikterus neonatorum adalah tertinggi ditemukan pada bayi dengan jenis kelamin laki-laki sebanyak 31 bayi dengan presentase $(64,6 \%)$.

Defisiensi G6PD yang merupakan suatu kelainan enzim tersering pada manusia dan berkaitan dengan kromosom sex (x-linked) yang umumnya hanya bermanifestasi pada laki-laki. Yang diduga hal ini terjadi karena defek yang terlalu berat terhadap aktifitas gengen pengkode enzim pada kedua utas rantai kromosom atau terjadi defek pula pada alel pasangannya yang diwariskan dari ibu sehingga tidak dapat menutupi atau menggantikan fungsi allele pasangannya yang telah rusak. ${ }^{5}$

Defisiensi glucose-6-phosphate dehydrogenase (G6PD) disebabkan oleh mutasi atau perubahan pada gen penghasil enzim G6PD. Mutasi pada gen tersebut menyebabkan penderita penyakit ini kekurangan atau tidak memiliki enzim G6PD sama sekali. Kondisi tersebut akan memengaruhi keberlangsungan hidup sel darah. Bila tidak memiliki enzim G6PD dalam jumlah yang cukup, sel darah merah akan lebih mudah pecah. Defisiensi G6PD lebih sering terjadi pada anak laki-laki. Hal ini karena gen penghasil enzim G6PD terdapat di kromosom X. Seperti diketahui, pria memiliki kromosom $\mathrm{XY}$, sedangkan wanita memiliki kromosom XX.

Penelitian ini sejalan dengan penelitian yang dilakukan Kamilah Budhi Rahardjani (2008) yang mengatakan bahwa penyakit ikterus neonatorum terbanyak pada bayi dengan jenis kelamin laki-laki sebanyak $85,1 \%{ }^{5}$

\section{Profil penderita Ikterus Neonatorum berdasarkan Berat Badan Lahir.}

Dari hasil penelitian ini menurut berat badan lahir terhadap kejadian ikterus neonatorum adalah tertinggi ditemukan pada bayi dengan berat badan lahir rendah (BBLR) sebanyak 26 bayi dengan presentase $(54,2 \%)$.

Sejalan dengan penelitian Nyun Astangunilah Yaestin (2017) sebanyak 31 bayi dengan presentasi $68,9 \%$. Bayi yang memiliki berat badan lahir rendah (BBLR) tanpa memandang masa gestasinya baik itu bayi prematur atau cukup bulan dapat menyebabkan tidak adanya atau berkurangnya jumlah enzim yang diambil atau menyebabkan pengurangan reduksi bilirubin pada bayi cukup bulan tetapi jangka waktunya lebih lama yang biasanya mengakibatkan kadar bilirubin yang tinggi. ${ }^{6}$

Kematangan pada organ bayi yang BBLR belum maksimal dibanding bayi yang memiliki berat badan lahir normal. Proses pengeluaran bilirubin melalui organ hepar yang belum matang menyebabkan terjadinya ikterus pada bayi. Sehingga terjadi 
penumpukan bilirubin dan menyebabkan warna kuning pada permukaan kulit. ${ }^{6}$

Sejalan dengan penelitian Nyun Astangunilah Yaestin (2017) sebanyak 31 bayi dengan presentasi $68,9 \%$ yang mengatakan bahwa Bayi Berat lahir rendah menderita ikterus neonatorum.

\section{Profil penderita Ikterus Neonatorum berdasarkan sepsis.}

Dari hasil penelitian menurut sepsist erhadap kejadian ikterus neonatorum tidak didapatkan pasien dengan sepsis sebanyak $100 \%$. Penelitian ini tidak sejalan dengan penelitian Kamilah Budhi Rahardjani (2008) yang mengatakan bahwa penyakit ikterus neonatorum terbanyak pada bayi yang mengalami sepsis sebanyak $57,6 \%$. $^{7}$

Walaupun sepsis menjadi salah satu penyebab terjadinya ikterus neonatorum namun pada penelitian ini tidak ditemukan.

\section{Profil penderita Ikterus Neonatorum berdasarkan Trauma lahir.}

Dari hasil penelitian menurut trauma lahir terhadap kejadian ikterus neonatorum tidak didapatkan pasien dengan trauma lahir sebanyak $100 \%$. Penelitian ini tidak sejalan dengan penelitian yang dilakukan Cholifah, Djauharoh dan Hanik Machfudloh (2016) yang mengatakan bahwa penyakit ikterus neonatorum yang disebabkan oleh trauma lahir sebanyak $7,3 \% .^{8}$

Walaupun trauma lahir menjadi salah satu penyebab terjadinya ikterus neonatorum namun pada penelitian ini tidak ditemukan.

\section{KESIMPULAN}

Berdasarkan hasil penelitian dari 48 penderita ikterus neonatorum yang dirawat di Bagian Kesehatan Anak RSU Anutapura Palu dan RSUD Undata Palu tahun 2019-2020 tentang Profil penderita ikterus neonatorum yang dirawat di Bagian Kesehatan Anak RSU Anutapura Palu dan RSUD Undata Palu tahun 2019-2020 kesimpulannya sebagai berikut:
1. Profil penderita ikterus neonatorum berdasarkan usia gestasi terbanyak pada bayi lahir kurang bulan sebanyak 33 bayi dengan presentasi $68,8 \%$ diikuti oleh bayi lahir cukup bulan sebanyak 15 bayi dengan presentasi $31,2 \%$.

2. Profil penderita ikterus neonatorum berdasarkan jenis kelamin yang terbanyak yaitu laki-laki sebanyak 31 bayi dengan presentasi 64,6\%.

3. Profil penderita ikterus neonatorum berdasarkan berat badan lahirterbanyak pada bayi dengan bayi berat lahir rendah (BBLR) sebanyak 26 bayi dengan presentasi $54,2 \%$ diikuti oleh bayi dengan berat badan lahir cukup sebanyak 17 bayi dengan presentasi $35,4 \%$ dan bayi dengan berat badan lahir sangat rendah sebanyak 5 bayi dengan presentasi $10,4 \%$.

4. Profil penderita ikterus neonatoum berdasarkan trauma lahir tidak ditemukan

5. Profil penderita ikterus neonatoum berdasarkan sepsis tidak ditemukan.

\section{DAFTAR PUSTAKA}

1. Kosim MS, Yunanto A, Dewi R, Sarosa GI, Usman A. 2014. Buku ajar neonatologi. ed. 4. Hal. 67-9.

2. Anggraini H. Faktor - Faktor Yang Berhubungan Dengan Kejadian Ikterus Pada Neonatal. Universitas Sumatera Utara. 2013. Hal 2-4

3. Ratuain MO, Wahyuningsih HP, Purnamaningrum YE.Hubungan Antara Masa Gestasi Dengan Kejadian Ikterus Neonatorum. Universitas . Vol. 7 no 1. 2012. hal 52.

4. Tazami RM, Mustarim, Syah S. Gambaran faktor risiko ikterus neonatorum pada neontus di ruang perinatologi RSUD Raden Mattaher Jambi tahun 2013. Jambi. 2013. Hal 3.

5. Rahardjani KB. Kadar Bilirubin Neonatus dengan dan Tanpa Defisiensi Glucose-6Phosphate Dehydrogenase yang 
Mengalami atau Tidak Mengalami Infeksi.

Semarang. Vol. 10, No. 2, Agustus 2008.

6. Yaesti NA, Hubungan Berat Badan Lahir Rendah Dengan Kejadian Ikterus di RS PKU Muhammadiyah Yogyakarta. Yogyakarta. 2017.

7. Pollard M. ASI Asuhan berbasis bukti, 2002. Hal 20-3.

8. Cholifah, Djauharoh, Machfudloh $\mathrm{H}$. Faktor-Faktor Yang Berpengaruh Terhadap Hiperbilirubinemia Di RS Muhammadiyah Gersik. Gresik. Hal 6 dan 7. 